\title{
WEDworks: Enhancing Participatory Drug Research and Prevention with Resources of the Roma Community. Effective Community-based Intervention Model and Practice Recommendations
}

\author{
Tzvetina Arsova Netzelmann ${ }^{1, *}$, Savka Savova ${ }^{2}$, Silvia Vassileva ${ }^{2}$, Joyce Dreezens-Fuhrke ${ }^{1}$, \\ Elfriede Steffan ${ }^{1}$ \\ ${ }^{1}$ SPI Forschung gGmbH, Germany \\ ${ }^{2}$ Health and Social Development Foundation, Bulgaria
}

Copyright $\bigcirc 2016$ by authors, all rights reserved. Authors agree that this article remains permanently open access under the terms of the Creative Commons Attribution License 4.0 International License

\begin{abstract}
Multiple social determinants e.g. poverty, lower education, unemployment aggravate the health inequities that the Roma population experiences in many European countries. Marginalized Roma communities in Central and Eastern Europe (CEE) face particular societal discrimination and limited access to health/social care, not least due to lacking health insurance. As a consequence young Roma suffer adverse health problems, including problematic drug use harms. The WEDworks project (Women, Ethnic Minorities, Drug-help Services) implemented a qualitative drug study among 123 Roma young people, 44 Roma parents and 23 local experts in Bulgaria, Latvia, Romania and the Slovak Republic. Based on its results gender-sensitive and needs-driven prevention actions were piloted. The interventions combined comprehensive setting-based approach on individual, family, and community levels with participatory behavior-change methods (popular-opinion-leader, peer drama and life-skills trainings) for prevention of drug use, HIV/STI and sexual health promotion. The main results were sensitization and mobilization of Roma community social networks for drug prevention and direct involvement of community young people in the co-shaping of the behavior-change process. Both research and prevention produced community- and resource-building effects and fostered inclusion and empowerment of vulnerable Roma youth. The formulated practice-driven recommendations support successful further roll-out of the piloted community-based model.
\end{abstract}

Keywords Participatory Health Research, Gender-sensitive Approaches, Community-based Drug and HIV Prevention, Ethnic Minorities, Roma, Vulnerable Young People

\section{Introduction}

Multiple social determinants e.g. poverty, lower education, unemployment, discrimination, aggravate the adverse health inequities of Roma communities. Furthermore, the lack of health/social insurance doubles their vulnerability to diverse health problems, including drug-use related harms. There is sufficient evidence that effective ethnic minorities' and migrants' health interventions rely on needs-driven response, community participation and empowerment strategies [1-4]. Nevertheless, despite their recognition as very important for the success of prevention programs, culturally-competent and migrant-friendly interventions and services are not per se based on true community participation. Wright [5] and collaborators clearly differentiate nine stages in their model of participation which mark the grade of participation, among informing and consulting a community (stages 4 and 5), co-determination of the course of action (stage 6) and participation based on decision-making power (stage 8).

Well advised by this stage model and by the core characteristics of the participatory health research [6], the WEDworks (Women, Ethnic Minorities, Drug-help Services) project developed and implemented a participatory approach for community-based drug prevention with marginalized Roma and other ethnic minority youth in four CEE countries. The two-year project WEDworks [7], funded by the European Union in the period 2013-2014, connected a social science research institute in Germany with civil society organizations in Bulgaria, Estonia, Latvia, Romania, and the Slovak Republic.

The 'red thread' underpinning the project's research and intervention actions was the gender-sensitive focus along with the participatory research and community-building standpoints. The applied science approach aimed at collaborative knowledge generation which shed light on 
needs and problems of the vulnerable ethnic minority communities, on gaps in prevention and care service or high service access thresholds respectively.

Ethnic minority background does not per se equal vulnerability to drug use. On the other hand, ethnicity is one important social determinant of health and vulnerability to risks and drug-related harms of minority and migrant communities.

Study findings of the European Monitoring Centre for Drugs and Drug Addiction (EMCDDA) [8] underline that ethnic minorities are exposed to specific risk factors and vulnerability to problematic drug use. Problematic family situation, poor education and problematic peer behavior are among the individual risk factors outlined. A special concern in drug research and prevention interventions deserve the 'specific groups of young people' including those in care institutions, early school leavers, homeless youth, young offenders and those coming from poor and economically disadvantaged neighborhoods and communities. Further data [ibid.] corroborates that members of some minority populations across EU, including Roma, are overrepresented in certain problem drug users' communities. At the same time they are exposed to marginalization and discrimination within their own minority communities, as drug use may be denied by their families and the community leaders. This fosters stigmatization, which in turn hampers help-seeking behavior and the support from the informal social networks within the Roma communities.

According to Glanz [9] the concept of community is integral to the discussion of effective behavior change and prevention models in minorities' and migrants' groups. They focus on the collective well-being of a community population and do not reduce it to vulnerable individuals or target groups. Typically defined in geographical terms, communities may be also based on shared needs, interests, practiced behavior or characteristics such as ethnicity, gender, sexual orientation, or occupation, as well as collective identity [9]. A substantial delineating feature of the community is the self-definition of its member as pertaining to one and the same 'social unity' and not be defined as such from outside as in the case of target group members.

Being in line with Glanz's community concept WEDworks' drug research and prevention interventions relied on community-building and empowerment components.

The aim was to conduct a qualitative research study with participatory elements in order to highlight gender-specific aspects of drug use among young people in Roma communities in Bulgaria, Latvia, Romania and the Slovak Republic. Further objectives of the study were to: identify problems and consequences related to substance use; analyze individual and community-related factors of vulnerability; map available prevention as well as support resources within the Roma communities. Alongside, the subjective meanings attributed to tobacco, alcohol and drug consumption and the related cultural values, norms and risk perception spread in the particular community were explored in depth.

\section{Materials and Methods}

\subsection{Study Settings and Respondents}

The study was performed in four neighborhoods with compact Roma population and distinct community structures: Fakulteta in Sofia, Bulgaria; the country town of Sabile in Latvia; Ferentary in Bucharest, Romania and Stara Tehelna in the region of East Slovakia. The four study sites were chosen on convenience grounds, as the research country partners operated their prevention and education programs within the selected neighborhoods and had established trustful and cooperative contacts with the Roma communities.

The study population sub-groups were defined a priory in line with the community-based approach aiming to address individual, family and community levels in the researched drug use topic. Given that Roma adolescents and young people were the primary target group for the project interventions the following breakdown of the study respondent groups was considered relevant: a) Roma children (10-14 years old) and adolescents (15-18 years old) and their informal friendship networks, b) Roma young people (18-25 years old) with substance use experience, c) parents of children/adolescents, and d) health, social or education experts and service providers in the respective communities.

\subsection{Study Design}

Based on the rapid assessment and response methodology [10] a mixed-method research design was selected combining guided individual semi-structured interviews and interactive focus groups with the use of storytelling and collages techniques. Uniform topic guides for interviews and focus groups were collaboratively developed by all research partner organizations and used in the field phase. A community-based participatory peer research complemented the method mix in one of the countries.

Through the visual-creative method 'photovoice' [11], 10 Roma adolescents in Bulgaria were trained and empowered to use photography and visual images to express their perception of the drug use problem in their community. The male adolescents shoot photos of their neighborhood exploring the places and means of drug use as well as the subjective meaning attributed to it. The visual materials and the follow-up reflection group discussions helped to outline relevant prevention themes, barriers, and resources. The research activity ended with a mapping exercise of the places related to drug use and risks within the Roma community.

\subsection{Study Sample and Recruitment Procedures}

The contacts to the different respondents' groups built 
upon the partly long-term and continuous services provided in the Roma communities either by the research partner organizations or by other civil society agents or local authorities. The recruitment approach chosen was via Roma community members, skilled and active as cultural mediators, health/education assistants, outreach workers or peer educators within the communities. They personally invited and motivated the participants to take part in the study or contacted them via other local community people, known for their informal (peer) leader role.

Given the qualitative type of the survey and the participatory health research features, a convenience sample based on principles of community-building and active involvement of key and committed community members was considered as appropriate for the research purposes.

The Roma children and adolescents were recruited according to two main inclusion criteria: ethnic background and age. The participants in the focus groups (10-14/15-18 years) had to represent the Roma adolescents in the community in general, being just 'regular young people'. For the group of young people (18 years and above) a third inclusion criterion was added to the latter: individual previous or present self-reported experience with substance use. The aim was to explore risk assumptions, practices and health-protective behavior of the elder community youth.

Furthermore, a balance between female and male respondents was also aimed at. While the younger age group (10-14 years) had a better balanced male-female ratio $(53 \%)$, the male adolescents made up two-thirds of the elder age groups (15-18, 18-25 years). The male respondents prevailed in particular among the young Roma people with substance use experience.

The inclusion criteria for Roma parents were to have at least one child in the age group 10 to 18 years and to live in the community. In most of the cases these were mothers.

The experts and service professionals were selected according to two criteria: experience with services for people using drugs and/or experience in direct work with Roma drug users or Roma community (Bulgaria, Slovak Republic). In Latvia the selected experts represented different professional backgrounds (social worker, police officer, cultural worker) and institutions (public authorities, non-governmental organization). Some of them were involved in support services for the Roma population in the Sabile municipality.

The field phase aimed to be six months (January-June 2014), but took nine months, so the study was finalized in September 2014.

Altogether 190 persons participated in the study in the four Roma communities through 19 focus groups, 21 interviews and one community-based participatory photovoice research group. 123 Roma adolescents and young people and 44 adolescents' parents were involved as well as 23 health, social care, educational experts and service providers, part of whom belonged as well to the Roma ethnic minority group.

Table 1. Study methods and sample per participating country

\begin{tabular}{|c|c|c|c|c|c|c|}
\hline Country & $\begin{array}{l}\text { Focus groups } \\
\text { with adolescents } \\
\text { Age 10-14 }\end{array}$ & $\begin{array}{c}\text { Focus groups } \\
\text { with young } \\
\text { people } \\
\text { Age 15-18 } \\
\end{array}$ & $\begin{array}{l}\text { Focus groups } \\
\text { with parents }\end{array}$ & $\begin{array}{l}\text { Focus groups } \\
\text { with experts }\end{array}$ & $\begin{array}{c}\text { Individual } \\
\text { interviews young } \\
\text { people Age 18-25 }\end{array}$ & $\begin{array}{l}\text { Photovoice } \\
\text { young people } \\
\text { Age 17-18 }\end{array}$ \\
\hline & FG participants & FG participants & participants & participants & participants & participants \\
\hline Bulgaria & 19 & 7 & 7 & 7 & 6 & 10 \\
\hline Latvia & 9 & - & 11 & 6 & 5 & - \\
\hline Romania & 10 & 10 & 10 & - & 5 & - \\
\hline Slovak Republic & 20 & 17 & 16 & 10 & 5 & - \\
\hline Total & 58 & 34 & 44 & 23 & 21 & 10 \\
\hline \multicolumn{6}{|c|}{ Total number of study participants } & 0 \\
\hline
\end{tabular}

* One focus group with parents \& experts per country. 


\subsection{Study Data Collection and Processing}

During the administration phase the field researchers followed strictly the principles of voluntary participation, informed consent and confidentiality. Prior to conducting the interviews and focus groups, informed consent was obtained from each participant, signed with pseudonyms or shorthand symbols to guarantee their anonymity. The field researchers read aloud the informed consent form to respondents with reading difficulties. For the participation of underage respondents the parents' consent was obtained in advance.

No personal data was collected. Both interview and focus group participants received an anonymous code, used in the subsequent analysis of the empirical data. The duration of each interview and focus group took one to one- and-a-half hours and the participants were offered refreshments, hot drinks and snacks. All Roma study respondents were granted incentives in the form of social aid vouchers or small cash remuneration (up to 10 Euro) as a compensation for their time and the shared life-world experiences.

The interviews and focus groups were audio recorded. The original audio material's transcription was verbatim or contents-wise in the case of redundant or study topic-irrelevant statements. The subsequent qualitative assessment was based on the grounded theory. To this end a special analysis grid was created by the project coordinator, SPI Forschung gGmbH Germany as an intermediary instrument of content analysis.

Some of the major relevant findings were compiled for the presentation in this article.

\section{Results}

\subsection{Study Results}

\subsubsection{Attitudes towards Substance Use and Subjective Risk} Perception

The first common trend observed in all four Roma communities was the particular tolerance within the community towards tobacco and alcohol consumption. Similarly the use of these substances was tolerated at family level as well. Parents did not consider that their own smoking and drinking behavior might impact negatively their children's behavior and did not believe that it could be a risk exposure facilitating factor. The supported social norms in the communities judged more strictly women who smoke or drink and treated them more rigorously than men.

As to the risk perception and attitudes towards alcohol some gender differences came to the fore. Unlike the boys, who mainly associated drinking with 'partying, sex, eroticism' or with a 'morning-after-headache', in Bulgaria the Roma girls associated the use of alcohol mainly with violence, aggression and loss of control and perceived it as a drug.

In addition, some inter-country differences were outlined as well. Thus, for instance, in Bulgaria and in the Slovak
Republic Roma adolescents, especially boys considered smoking and drinking particularly fashionable and socially prestigious. The male adolescents did not conceal their use of legal substances. On the contrary, aspirations for greater independence and social appeal were attributed to it. They reported to be neither encouraged nor sanctioned by the community for such behavior. The Roma adolescents in Romania outlined an opposite trend, expressing negative attitudes towards smoking and drinking. They supported the view that the onset of substance consumption should the postponed as much as possible.

The research findings proved that Roma adolescents' and young people's knowledge about different types of drugs was generally insufficient, not detailed and intertwined with false beliefs (Latvia, Bulgaria, and the Slovak Republic). Besides, as mentioned above, no risks were associated with smoking and drinking alcohol, neither by the adolescents nor by their parents.

For most of the young Roma the only connotation of drugs and related harms was limited to the illicit substances (e.g. opioids), or particular consumption patterns (e.g. injecting heroin). Injecting drugs has been pointed out by the Roma survey participants in Bulgaria and Latvia as the riskiest drug use, a practice that inevitably leads to serious irreversible dependency. Particularly striking was the generally positive attitude towards the so-called party drugs.

"I would never try drugs, because it is very dangerous, you can die - if you start, you are not able to stop until you die, and the other stuff [other substances except heroin] I can stop whenever I want." (a young Roma man with drug use experience in Bulgaria).

The use of other substances, or even heroin, when not injected, is not associated with risk exposure and harms for the health of the user. Young Roma men from Bulgaria favored the false belief that sniffing, smoking, or inhaling heroin does not lead to addiction and could not be life-threatening.

"I do not think using amphets [amphetamine] is dangerous, on the contrary, I believe it's even useful - it helps when you have sex, I can have sex for one hour, if I've smoked grass [cannabis] I cannot stand so long". (a male Roma adolescent in Bulgaria)

Studying the gender aspects highlighted clear differences in the substance use experience of boys and girls as to the onset, frequency and contexts of consumption. Furthermore, the communities show different tolerance, putting different norms in practice for boys and girls. In all the studied Roma communities women's substance use was considered less acceptable than men's one (Latvia, Romania, Bulgaria, and the Slovak Republic).

“...Women must not cross the limit... women should be more restrained, to keep their distance". (a focus group with parents from Roma community in Latvia) 
Widespread was the perception that drug using women tend to have a provocative behavior. Therefore they were being accused of low morale and treated defamatorily as 'prostitutes'. Seen as a 'shame' for the family young drug using women face strong discriminating attitudes from the other community members.

"A girl who is using drugs cannot get married because no one will be willing to take her as she is considered unable to have healthy children. If she succeeds to get married anyhow and her husband finds out that she is using drugs, he would send her back to her mother, who would be unwilling to take her back because this is a big shame". (a focus group with parents in Roma community in Bulgaria)

\subsubsection{Patterns of Consumption and Community Norms}

Some regional differences could be depicted with regards to the illicit drugs used in the studied communities.

Table 2. Most commonly used substances in the Roma communities (self-reported)

\begin{tabular}{|c|c|}
\hline Country & Substance type/s \\
\hline Bulgaria & $\begin{array}{c}\text { Cannabis (marijuana), stimulants ('party drugs' } \\
\text { e.g. amphetamines, ecstasy, cocaine), opioids } \\
\text { (heroin) or poly-drug use. }\end{array}$ \\
\hline Latvia & $\begin{array}{l}\text { Cannabis (marijuana), hallucinogens (LSD), } \\
\text { stimulants ('party drugs', though reported to be } \\
\text { used by the young people only a few times in a } \\
\text { lifetime) }\end{array}$ \\
\hline Romania & $\begin{array}{c}\text { Cannabis (marijuana), stimulants, new } \\
\text { psychoactive substances ('legal highs'), opioids } \\
\text { (smoking, injecting heroin) }\end{array}$ \\
\hline $\begin{array}{l}\text { Slovak } \\
\text { Republic }\end{array}$ & $\begin{array}{l}\text { Toluene (methylbenzene, fenylmetán, formerly } \\
\text { known as toluol, with abbreviation } \mathrm{Ph}-\mathrm{Me} \text { ) }\end{array}$ \\
\hline
\end{tabular}

A pattern of gradual experimentation with substances was observed, tobacco and alcohol being the 'gateway' drugs - at the age of 10 years in Latvia, 7-8 years in Bulgaria for the boys, and 6-7 years in the Slovak Republic. The so-called soft 'party drugs' (cannabis) were consumed for the first time between 14-19 years and the 'heavy drugs' (amphetamine, heroin, cocaine) - at the age of 20 years in Latvia, and 16-18 years in Bulgaria.

The most frequently used and known substance in the Roma communities was cannabis. The Bulgarian male respondents from both focus groups and individual interviews confirmed that marijuana was easily accessible in the Roma neighborhood, being the cheapest and least problematic to obtain.

"It is very easy to buy weed [cannabis] in the neighborhood. We get together 8-10 people, each one of us gives what he has, and we can just buy it... this way we have enough for the day." (a young Roma man from Bulgaria)

The widespread everyday use of cannabis is supported by positive attitudes that "it is good for the health", because it "cleans the blood". It is generally not considered a drug, as the male adolescents and young men are convinced that one cannot get addicted to it. The main sources of information about drugs are the informal networks and friends. This contributes to spread and solidify false beliefs, myths and irrelevant information concerning drugs and their harmful consequences (Bulgaria, Romania, Slovak Republic, and Latvia).

A common trend registered in Bulgaria, Romania, and Latvia was the decrease of heroin use in the Roma communities over the last years. This was explained with the effective problem-solving measures at community level to expel the heroin dealers from the community (Bulgaria) or presented a result of the joint efforts of local authorities, police monitoring and interventions.

According to respondents' reports female adolescents would start their drug use a few years later than the males. The respondents in all the studied Roma communities suggested that the number of female drug users is considerably smaller than that of male users.

The influence of the social context and peer group were pointed out as the most powerful factors in the drug use initiation along with the generally easy access to the substances. Influential community members, either adults or peers, play as a crucial role model hereby.

"In principle, all the LSD, marijuana... it's under the influence of friends... because it was actually quite popular in... Here is the group, they have drugs with them - and go on... Did not have any choice try or not to try. If all are using, then really everyone should do this... the 'swarm instinct'.... It was the impact... yes... you just... wanted to be like the local leader... " (a male Roma interview partner in Latvia)

Along with the natural adolescents' curiosity the urging desire for new experiences and fun (Bulgaria, Latvia, Romania, and the Slovak Republic) or the wish to escape from everyday-life problems were outlined as main driving factors towards experimentation with substance use. Juxtaposing the driving motives of boys and girls another gender difference could be outlined. A frequent reason for girls and young women to start using substances was their partner - the boyfriend or the husband, either because of the wish to share experience and emotional closeness or out of disappointment and emotional distress after separation/being abandoned. Not a rare phenomenon in some Roma communities was the involvement of other family members in drug use, such as mothers, grandmothers and wives as a sign of solidarity with the drug using men in the family (Bulgaria, Slovak Republic).

Having poor social skills was considered a vulnerability factor. As emphasized by survey respondents many youngsters lack assertiveness and resilience to withstand peer pressure. The teenagers with lower level of social skills have tried all kind of drugs more often than youngsters/school students with higher level of social skills (Latvia, Bulgaria). Further vulnerability factors named were the poor parental control, having a family member with drug problem or generally problematic family context. Thus, the 
young people in Romania pointed out that children of parents who work abroad, who grow up with their grandparents, or children in single-parent households were more exposed to risks of drug use than children who live with their two parents.

The survey corroborated that the Roma parents lack basic knowledge about illicit drugs. They often referred to common myths about drugs treating them as objective and reliable information (Romania, Bulgaria, and Latvia). Generally considered a socially undesirable behavior, drug use was preferably not to be attributed to their own community and children. The occurrences of the phenomenon were frequently suppressed or concealed.

"In our neighborhood we are drinkers but not junkies.” (a focus group with parents from Roma community in Bulgaria)

Drug addiction being associated with shame within the Roma community was used by some parents to differentiate between the 'normal' community and those in its margins, who live 'in a parallel world'. There were whole families or sub-neighborhoods involved in drug use and/or its supply. According to the extent of the problem communities were divided in two parts - 'the good and decent' and the 'bad' ones (Slovak Republic, Romania). Known for their asocial or delinquent behavior and the stains for the community's reputation drug users were nevertheless silently tolerated since they keep living on the margins. As long as the own children did not interact with peers from the segregated parallel world of the users, they were not considered vulnerable to drug-related risks and harms.

"[We are] parallel people, different worlds. Everyone does what they want with their own life. There are [the drug users] still here, on our street. But it is not a problem which would affect everybody." (Roma mother from Romania)

From all the Roma parents only those in Latvia conceded that negative parental examples with substance use could encourage young people to start using drugs. At the same time parents were unequivocally convinced that the family and close relatives play a pivotal role in drug prevention and health education of the child compared to the school and the state social system (Romania, Latvia, and Bulgaria).

Looking at the findings from all four countries the ethnic background did not stick out as the major determinant of vulnerability for substance use. Our results are in line with the data of the European School Survey Project on Alcohol and Other Drugs (ESPAD) [12] framing the general population trends for the four countries involved in the survey. The drug users were predominantly men, but there was a higher proportion of women from ethnic minority communities engaged in drug use, compared with the general the population.

\subsubsection{Problems Related to Drug Use and Help-seeking Behavior}

Most of the problems related to drug use in Roma communities do not differ from those of the drug users in general. Nevertheless, the Roma drug users face specific obstacles which rise from the underprivileged status of the community as a whole and their socially disadvantaged personal situation. Many problems that aggravate the general health conditions of Roma drug users are linked to the limited access to social and health services. The latter results from poor social integration of the Roma communities and the casual interlink of multiple adverse social determinants early school drop-out, lack of occupational skills, unemployment, precarious economic situation, bad living conditions, loss of entitlement to social welfare benefits and health insurance.

The field research in Bulgaria and the Slovak Republic shed light on some of the drastic complex problems entangling addicted young users into vicious circles, difficult to break out from. The drug using respondents described that their whole social life pivots on the consequences of their addictive behavior. Most of them left school early (often even primary school) without any certificate, did not have or planned to acquire any occupational training and lived on the street. The interviewed Roma drug users (all male) in Bulgaria reported that they systematically engaged in paid sexual services to other men as means to finance their drug habit. However, most of them did not consider this as sex work, as the majority of them referred to regular clients they would just 'work with'.

In the Slovak Roma community the excessive use of poor quality alcohol and harmful drugs had detrimental consequences against the background of the immense poverty, substandard living conditions and the very young age of users' initiation. Among these were extensive health problems, co-morbidity (e.g. HIV, Hepatitis), mental illnesses, aggressive and criminal behavior, and not least high rates of youth mortality.

Besides, risky drug use practices and overdose were referred to as frequently occurring within the drugs users' communities in all country settings. Another conspicuous similarity could be identified among the vulnerable Roma drug users in the lack of awareness, motivation and hopefulness with regard to help-seeking behavior and support services in general. Only in Romania could a support factor for coping resources' mobilization of the problem drug users be named. Injecting drug users who were parents stated to be motivated to look for and enroll in rehabilitation or harm reduction services. In the name of their own children they put efforts together to minimize the negative impact of their addiction.

At the same time the study compiled evidence on the restricted access and high thresholds of the drug help and rehabilitation services in the four surveyed countries. Only two of the country research teams (Bulgaria, Romania) reported on harm reduction/maintenance services existing in the Roma community or being community-based. Some of those services were run by the CEE research partners themselves as civil society organizations. No local public drug help services with special offers tailored to the needs 
and particular life circumstances of Roma drug using clients could be identified. This result is confirmed by the European case study report of EMCDDA [8] examining the drug interventions for minority ethnic populations in 29 European countries. The study found that only five countries included interventions targeted specifically to Roma, only Latvia from the survey countries being among them.

Roma drug users and in particular young vulnerable users experience major barriers to harm reduction and rehabilitation services. Harm reduction services including substitution (Methadone programs) treatment are available for people with identification documents and for minors with parental consent, above 16 years of age. Being a young drug user may limit the access to harm reduction services, as young people were often reluctant to disclose their behavior to their parents or relatives. There are no specialized drug treatment programs for Roma communities. The access to the mainstream rehabilitation and substitution treatment programs is limited due to a number of factors such as lack of information (Latvia), identity papers (Romania), health insurance, financial resources (Bulgaria, Slovak Republic) for enrolment in a paid service and limited places as well as long waiting lists in the cost-free programs (Bulgaria, Romania).

\subsection{Intervention Results}

Given the practice-driven nature of WED works intervention our drug research actions and their findings were directly intertwined with drug prevention activities. The jointly gained knowledge and expertise about the drug-use problem was 'translated' into practical steps towards Roma community mobilization and involvement in the drug prevention. Following the setting intervention approach the activities were divided at individual, family and community level and adjusted to the age groups of the participants as well. Evidence-informed innovative behavioral change methods ('popular-opinion-leader') were piloted along with prevention and competence building methods transferred from formal education settings into the communities (peer drama and life-skills trainings). Their implementation was guided by the principles of human rights, voluntary participation, equity, gender responsiveness, meaningful involvement and empowerment and aimed ultimately at social network mobilization and improvement of young people's agency.

Eventually around 200 Roma community members children, adolescents, young people and parents were involved in more than 20 community prevention trainings and interactive events in the four countries. Here are some examples:

Peer drama: Based on the methods of community theatre peer-drama training was conducted with 10 Roma children aged 8-12 years in Bulgaria for preparation of a theatre performance based on the 'Snow white' fairy tale. It reached 40 further children and adolescents with a prevention message focusing healthy choices in the Roma community.

POL: The 'popular-opinion-leader' (POL) is a prevention model based on the social diffusion theory [13]. It was applied in Bulgaria for behavior prevention and resource mobilization of young people's informal networks. Two POL training groups were implemented with 20 young Roma males aged $16-18$ years.

Life-skills: Based on the training curriculum of the Council of Europe [14] seven life-skills trainings were conducted with 84 Roma adolescents aged between 10 and 16 years in Bulgaria, Latvia, Romania and Slovak Republic. The training themes encompassed: self-reflection and self-presentation skills, values, emotions, aims setting and achievement, time management, sexual and reproductive health, HIV and STIs, substances, drug use and related risks, communication, decision-making and assertiveness, tolerance and empathy.

Parents' involvement: Two parents support groups with 24 parents of the life-skills trainees were conducted in Bulgaria.

Community campaign and production of prevention materials: In all four partner countries drug prevention materials have been developed with the active creative participation of the Roma adolescents. Special prevention events, like tree planting actions, outdoor sport feasts and mountain excursions complemented the community activities offering alternative leisure time and meaningful involvement options for the Roma young people.

\section{Conclusions}

Summing up the conclusions, both research and prevention interventions produced community- and resource-building effects in the participating Roma communities from the four CEE countries. Civil society and community resources for diversified drug-help measures were mobilized and the project strengthened the local practice evidence on collective and multi-perspective prevention interventions. Moreover, a shared ownership of the action and its results was achieved among the community members, field researchers and partner organizations. The multi-method interactive activities were conducted by community members for community members, so that the beneficiaries became the co-authors of change. The successfully piloted methods addressed easy-to-change factors at both community and individual levels showing cost-effectiveness at the same time.

Their sustainable dissemination and scaling-up in other vulnerable Roma communities would contribute to quality improvement of health promotion and prevention programs, fostering more effective inclusion of Roma communities that is much needed in a time of economic hardships and social discrimination.

\section{Practice-driven Recommendations}

Based on the local evidence collated by the WED works 
actions, the lessons and insights gained in the situation of young Roma's drug use and their lived-in experiences we formulated a set of practice recommendations. They aim at improved gender-sensitive focus and community participation in the design of effective drug prevention interventions with Roma communities.

The drug prevention interventions within Roma communities have to:

- be adjusted to the local context as well as to the community norms, values and practices with special focus on the gender perspective and attentiveness to girls' and young women's participation;

- address both individual, family and community level of involvement as well as utilise the resources of existing community services, cultural and faith-based centers;

- be authentically related with the community through participatory involvement based on trust and confidential contacts, recognition and promotion of positive role models and examples from the community;

- ensure greater involvement of young popular opinion leaders as peer role models in drug and HIV prevention work, tailoring prevention messages and behavior change interventions;

- ensure continuous skills building and training offers out of school setting for the community youth, especially for early school leavers;

- envisage appropriate youth-friendly prevention and education materials which are methodically variable, culturally, linguistically and visually relevant;

- engage young people and their informal social networks in design and implementation of regular campaigns addressing their peers with healthy lifestyle messages, alternative models of entertainment and youth activities, meaningful involvement and solidarity with vulnerable community members;

- improve visibility and accessibility of the help services existing community e.g. counseling and testing (HIV/STIs), sexual health and drug help in a user-friendly manner and build bridges to the system of mainstream health/social services;

- put efforts in building/boosting interdisciplinary cooperation with other relevant programs/services that aim at improved education, employment and social inclusion chances at community level;

- commit to continuous advocacy actions for protection of human rights and non- discrimination of Roma communities and de-stigmatization of most vulnerable community members.

\section{Acknowledgements}

The authors gratefully acknowledge all contributions to the research and prevention actions of WED works made by the CEE partner organizations: HESED (Bulgaria), Papardes Zieds (Latvia), ARAS (Romania) and PRIMA (Slovak
Republic). We sincerely thank all Roma community members who participated in the survey and the co-acting experts and service providers on the spot.

\section{REFERENCES}

[1] H. von Unger, T. Gangarova. PaKoMi Handbuch: HIV-Prävention für und mit Migrant/inn/en, Deutsche AIDS-Hilfe e.V., Berlin, September 2011.

[2] R. Antonova, S. Lex, S. Vassileva, R. Salman, J. Kalikov, S. Blumberg, T. Gangarova, H von Unger, J. Dreezens-Fuhrke. From Culturally Sensitive to Community-Based. A Practical Manual on Effective Models of Participatory Community-Based HIV/STI Prevention in Migrants/Ethnic Minorities, Health and Social Development Foundation, Sofia, 2012.

[3] E. Steffan, T. Arsova Netzelmann, R. Antonova. From Culturally-sensitive to Community-based? Correlation Conference, Ljubljana, 2011.

[4] T. Arsova Netzelmann, J. Dreezens-Fuhrke, S. Vassileva. WED works: Enhancing participatory drug research and prevention with resources of the Roma community: A community-based intervention model in 'Fakulteta', Sofia. 5th EUPHA European Conference on Migrant and Ethnic Minority Health, EASP, Granada, 2014.

[5] M. T. Wright, M. Block, H. von Unger. Partizipation der Zielgruppe in der Gesundheitsfördernd und Prävention. In: M.T. Wright (Ed.). Partizipative Qualitätsentwicklung in der Gesundheitsförderung und Prävention, Verlag Hans Huber, Bern, 2010.

[6] M. T. Wright. Was ist Partizipative Gesundheitsforschung? Positionspapier der International Collaboration for Participatory Health Research. Springer Verlag Berlin Heidelberg, Prävention und Gesundheits förderung 3, $8: 122-131$ 2013, 2013.

[7] Online, Available: http://www.wedworks.eu.

[8] Thematic Papers: Drug prevention interventions targeting minority ethnic populations: issues raised by 33 case studies. European Monitoring Centre for Drugs and Drug Addiction (EMCDDA), Lisbon, 12-13, 2013.

[9] K. Glanz. Community and group models of health behavior change. In: K. Glanz, B. K. Rimer, K. Health Behaviour and Health Education. Theory, Research and Practice. Josse-Bass, 4th Edition, San Francisco, CA, 2008.

[10] SEX-RAR Guide: The Rapid Assessment and Response Guide on Psychoactive.

[11] Substance Use and Sexual Risk Behaviour. World Health Organizations (WHO), Geneva, 2002.

[12] C. C. Wang, S. Morrel-Samuels, P. M. Hutchison, L. Bell, R. M. Pestronk. Flint Photovoice: Community Building Among Youths, Adults, and Policymakers, American Journal of Public Health, Vol. 94, No. 6, 911-913, 2004.

[13] J.A. Kelly. Popular opinion leaders and HIV prevention peer education: resolving discrepant findings, and implications for the development of effective community programmes, AIDS Care: Psychological and Socio-medical Aspects of 
AIDS/HIV, Vol.16, Issue 2, 139-150, 2004.

[14] R. Ives. Life-skills training in schools Manual. Council of
Europe, Pompidou Group, P-PG/Prev-LS(2005)1. Online Available: https://wcd.coe.int/ViewDoc.jsp?id=1301195\& Site $=$ COE . 